\title{
Animal models of contraception: utility and limitations
}

This article was published in the following Dove Press journal:

Open Access Journal of Contraception

17 April 2015

Number of times this article has been viewed

\section{Emma R Liechty' \\ Ingrid L Bergin' \\ Jason D Bell ${ }^{2}$}

'Unit for Laboratory Animal Medicine, ${ }^{2}$ Program on Women's Health Care Effectiveness Research, Department of Obstetrics and Gynecology, University of Michigan, Ann Arbor, MI, USA
Correspondence: Jason D Bell

Department of Obstetrics \& Gynecology, University of Michigan, I500 E. Medical

Center Drive, Ann Arbor, MI, 48I 09, USA

Tel + I 7342323897

Fax +I 7346479727

Email jasonbel@med.umich.edu
Abstract: Appropriate animal modeling is vital for the successful development of novel contraceptive devices. Advances in reproductive biology have identified novel pathways for contraceptive intervention. Here we review species-specific anatomic and physiologic considerations impacting preclinical contraceptive testing, including efficacy testing, mechanistic studies, device design, and modeling off-target effects. Emphasis is placed on the use of nonhuman primate models in contraceptive device development.

Keywords: nonhuman primate, preclinical, in vivo, contraceptive devices

\section{Introduction}

There is an urgent need for investment in preclinical development of novel contraceptive methods. Despite an increase in the variety of available contraceptive products, nearly half of pregnancies in the USA are unplanned. ${ }^{1}$ Unintended pregnancy is associated with significant public health consequences, including increased risk of low infant birth weight, preterm delivery, and maternal depression. ${ }^{2}$ Contraceptive choice and effective use is associated with a wide range of variables, including but not limited to, socioeconomic characteristics, ${ }^{3}$ childbearing goals, ${ }^{4}$ and method-specific experiences or attitudes. ${ }^{5}$ This variability suggests that increased contraceptive choice may improve usage and compliance; however, newly marketed contraceptive products are often variations in the dose and delivery method of well-established steroidogenic products. $^{6}$

Barriers to development of novel contraceptives have been multidimensional, including regulatory and corporate limitations. ${ }^{7}$ One difficulty originates from the unique character of newer contraceptives, which combines aspects of pharmaceuticals, biologics, and devices in a single medical product. Therefore, development and optimization of these products includes not only evaluation of pharmacokinetics, toxicology, efficacy, and mechanisms of action, but must also consider device design and user acceptability. These aspects can be challenging to interrogate, but their successful preclinical modeling increases the likelihood of success in human clinical trials.

In this review, we draw on examples of contraceptive modeling in multiple species to illustrate how challenges to preclinical development have recently been addressed. We begin with a brief discussion of the utility of rodent and nonhuman primate species for discovery of novel contraceptive targets, as well as means by which contraceptive efficacy is evaluated in preclinical models. We move on to discuss species-specific anatomic and physiologic considerations impacting evaluation of contraceptive 
device design and mechanism of action. Finally, we review models used for characterization of extra-contraceptive effects. Emphasis is placed on nonhuman primate models for contraceptive device development. Normative reproductive values for species used in contraceptive modeling are summarized in Table 1.

\section{Contraceptive discovery}

Characterization of processes underlying folliculogenesis, ovulation, luteal maintenance, and implantation in animal models has facilitated identification of potential pathways for contraceptive intervention and assisted reproductive technologies. ${ }^{8}$ In order to achieve a contraceptive effect with minimal side effects, the expression and function of these targets should be unique to the reproductive tract or pathway. Ideally, an event occurring near fertilization is targeted in order to avoid affecting early gametogenesis. ${ }^{7}$

Rodent models are well suited for in vivo contraceptive target discovery. The availability of advanced genetic engineering technologies, such as CRISPR/Cas systems, ${ }^{9}$ as well as resources for comprehensive phenotypic analysis $^{10}$ of genetically engineered mice facilitate discovery of fertility and contraceptive targets. ${ }^{11}$ These targets fall across the hypothalamic-pituitary-gonadal axis and include a number of reproductive modulatory strategies, including vaccines, receptor antagonists, and hormonal analogs. Immunocontraceptive targets include zona pellucida glycoproteins, ${ }^{12}$ spermatic antigens, ${ }^{13}$ or hormones such as gonadotropin-releasing hormone or human chorionic gonadotropin. ${ }^{14}$ Receptor-level modulation has been attempted at endometrial targets necessary for receptivity and decidualization, such as tissue-specific serine proteases, ${ }^{15,16}$ follicle-stimulating hormone, ${ }^{17,18}$ prostaglandin E2, ${ }^{19}$ and progesterone receptors. ${ }^{20}$

Due to similarities with human reproductive anatomy and physiology, contraceptive target discovery also occurs in nonhuman primate species. For example, mRNA expression of eight proteases was upregulated 12 hours postovulation in rhesus macaques subjected to an ovulatory stimulation protocol. Moreover, direct follicular injection of a metalloproteinase inhibitor prior to ovulation was associated with inhibition of follicular rupture. ${ }^{21}$ Similarly, pre-ovulatory gonadotropin surges potentiate phosphodiesterase 3A-mediated oocyte maturation. ${ }^{22}$ Treatment of female macaques with a phosphodiesterase inhibitor was associated with a reduced rate of pregnancy in one preclinical trial. ${ }^{23}$ Antagonism of endometrial targets necessary for implantation, such as leukemia inhibitory factor ${ }^{24}$ or vascular endothelial growth factor, ${ }^{25}$ has also undergone proof of concept testing. Development of compounds with antagonistic or modulatory activity at the progesterone receptor (antiprogestins, progesterone receptor modulators) has been evaluated in nonhuman primates as well as rodents. Parenteral administration of an antiprogestin is associated with reversible suppression of menstruation in artificially cycled rhesus macaques. ${ }^{26}$ Similarly, intrauterine delivery of two antiprogestins, ulipristal acetate ${ }^{27}$ and Schering ZK $230211,{ }^{28}$ has been evaluated in ovariectomized, artificially cycled rhesus and stump-tailed macaques, respectively. In both cases, endometrial atrophy and amenorrhea were associated with intrauterine administration of a range of doses.

\section{Contraceptive efficacy}

Preclinical evaluation of contraceptive efficacy presents many challenges to the investigator. When selecting a model species, differences in reproductive physiology should be taken into consideration. Rodent ovarian follicular dynamics differ from those of monovulatory nonhuman primates in several important ways, including follicular size, number of follicles released, and hormonal control of ovulation and luteal maintenance. ${ }^{29}$ A post-copulatory prolactin surge is

Table I Comparison of normative reproductive values in species used for contraceptive modeling

\begin{tabular}{|c|c|c|c|c|c|c|}
\hline Species & Common name & $\begin{array}{l}\text { Adult } \\
\text { female } \\
\text { size }(\mathrm{kg})\end{array}$ & $\begin{array}{l}\text { Median ovarian cycle } \\
\text { length (days) }\end{array}$ & Breeding seasonality & Menstruation & $\begin{array}{l}\text { Gestation } \\
\text { length } \\
\text { (days) }\end{array}$ \\
\hline Macaca fascicularis & Cynomolgus macaque & $2.5-5.7$ & 29.4 & Year-round breeder & Yes & 164 \\
\hline Macaca nemestrina & Pig-tailed macaque & $4.7-10.9$ & 32 & Year-round breeder & Yes & 170 \\
\hline Macaca mulatta & Rhesus macaque & 5.3 & 28 & Seasonal breeder & Yes & 165 \\
\hline Papio anubis & Olive baboon & $14.7-17$ & 30 & Year-round breeder & $\begin{array}{l}\text { Yes; difficult to } \\
\text { visualize }\end{array}$ & 170 \\
\hline Mus musculus & Mouse & $0.018-0.035$ & $4-5$ & Year-round laboratory & No & $|9-2|$ \\
\hline Rattus norvegicus & Rat & $0.25-0.35$ & $4-5$ & Year-round laboratory & No & $21-23$ \\
\hline Oryctolagus cuniculus & Rabbit & $2-5$ & $\begin{array}{l}\text { Post-copulatory ovulation } \\
\text { with sexual receptivity } \\
\text { every } 4-17 \text { days }\end{array}$ & Year-round laboratory & No & $30-33$ \\
\hline
\end{tabular}


required for luteal development in rodents, while a midcycle luteinizing hormone (LH) surge is sufficient amongst primates. ${ }^{30}$ Old World monkey species, such as macaques and baboons, exhibit pituitary release of $\mathrm{LH}$ and gonadal LH receptor morphology that closely resembles that observed in humans. Conversely, New World monkey species, such as marmosets and squirrel monkeys, release chorionic gonadotropin from the pituitary and express a modified form of the gonadal LH receptor. ${ }^{31}$

Prospective evaluation of contraceptive efficacy is difficult in women. In Phase I and Phase II clinical trials, markers of reduced fertility, such as ovulatory or spermatogenesis rates, are utilized in place of pregnancy. ${ }^{7}$ The use of pregnancy as an endpoint is a significant advantage in animal modeling of contraceptives. For example, Peluffo et al evaluated a prostaglandin E2 receptor 2 antagonist in a contraceptive trial with cynomolgus macaques. ${ }^{19}$ Following pretrial treatment, group-housed females were introduced to a single male. Pregnancy was detected via serum progesterone and macaque chorionic gonadotropin levels and viability was confirmed with abdominal ultrasound. Pregnancies were terminated prior to 32 days' gestation with parenteral mifepristone or intrafetal methotrexate. ${ }^{32}$ Thirty-eight percent of macaques receiving the prostaglandin E2 receptor 2 antagonist became pregnant in comparison with $80 \%$ in the vehicle-treated control group. In rodents, quantitative evaluation of contraceptive efficacy is easily determined by comparison of implantation rates in control and experimental uterine horns at necropsy. However, when evaluating preclinical contraceptive efficacy in rodents, investigators and regulatory bodies must define acceptable levels of reduction in gestational rates in these polyovulatory species.

In addition to use of pregnancy as an endpoint, animal modeling permits standardization of ovarian cyclicity. Ovarian cycle length can be synchronized through provision of exogenous hormone in ovariectomized macaques. This is typically performed in seasonally anovulatory species, such as rhesus macaques. In this protocol, animals are implanted with a subcutaneous capsule of estradiol for 14 days. A capsule containing progesterone is added from days 14-28, and then removed to stimulate menstruation. This protocol has been successfully used to synchronize and control ovarian cycle variability in a cohort of macaques prior to a contraceptive trial. ${ }^{28}$ Disadvantages include potential impacts of exogenous progesterone, such as vaginal epithelial thinning and differences in background hormonal milieu, between ovariectomized and intact animals, as Old World primate species have a large circulating pool of adrenal-origin androgen. ${ }^{29}$
Where collection of preovulatory follicles for in vitro analysis is of interest, a controlled ovarian stimulation protocol has been described for the rhesus and cynomolgus macaque. ${ }^{19,33}$ In these protocols, injection of human chorionic gonadotropin is followed by a course of recombinant human follicle-stimulating hormone, a gonadotropin-releasing hormone antagonist for prevention of endogenous gonadotropic surge, and finally a single preoperative dose of recombinant LH to promote follicular maturation without rupture. This protocol facilitates progressive development of a dominant follicle, but replaces endogenous LH with exogenous human chorionic gonadotropin in order to control the timing of ovulation. ${ }^{30}$

Where exogenous control of ovarian cycle is not desired, cycle monitoring is often still critical to the study of contraceptive efficacy. In rodents, the ovarian cycle is noninvasively monitored through cyclical changes in vaginal cytology. ${ }^{34}$ In Old World monkey species with menses, swabs of the vaginal anterior fornix can be examined for the presence of blood or sperm when animals are being bred. Alternatively, the external genitalia can be visually examined. In baboons, menses may be difficult to visualize. Rather, perineal skin tumescence is reliably used as a visual proxy for the ovarian cycle. ${ }^{35}$ External observations may be complemented by fecal, urine, or serum hormonal assays in most nonhuman primate species. ${ }^{36-38}$

\section{Contraceptive device design}

Due to their similarity to human reproductive anatomy and physiology, nonhuman primates are advantageous for latestage preclinical evaluation of both contraceptive design and efficacy. Preclinical safety and feasibility is generally evaluated in rodents and rabbits. These species are advantageous due to the presence of dual uterine horns, a short ovarian cycle, and reduced cost relative to nonhuman primates, although challenges with device scale and differences in reproductive physiology may limit the translational value. Model characteristics are summarized for each contraceptive device in Table 2. For the purposes of this discussion, contraceptive devices will refer to both hormonal and nonhormonal intrauterine devices (IUDs), intravaginal rings, transdermal patches, and subcutaneous implants. Nonhormonal barrier methods such as condoms or diaphragms will not be discussed.

\section{Intrauterine devices}

Intrauterine contraception currently available to consumers in the USA includes two levonorgestrel intrauterine systems (LNG-IUS) and a copper IUD, the T380A (Paragard ${ }^{\circledR}$; Teva 
Table 2 Comparison of animal models of contraceptive devices

\begin{tabular}{llll}
\hline Device & Species & Advantages & Disadvantages \\
\hline IUD & Baboon & $\begin{array}{l}\text { Size permits human-use IUD } \\
\text { Transcervical deployment possible } \\
\text { Year-round breeder } \\
\text { Well characterized }\end{array}$ & Expensive \\
& Rodent & Less expensive & $\begin{array}{l}\text { Expensive } \\
\text { Hysterotomy placement of IUD } \\
\text { Some species are seasonal breeders }\end{array}$ \\
& Macaque & Well characterized & Filamentous or rod IUD only \\
& Validated ring for NHP use & Hysterotomy placement of IUD \\
IVR & Well characterized & Ring is smaller than human model \\
& Sheep & Similar body mass to human & More basic vaginal pH than human \\
& Less expensive than NHP & Seasonal breeders IUD, NHP \\
Transdermal delivery & Well characterized in in vitro and in vivo assays & Not well characterized \\
systems & Resembles human skin & Expensive \\
& Macaque & Resembles human skin and reproductive physiology & Expensive \\
& Rabbit & Less expensive & More heterogeneous drug absorption \\
\hline
\end{tabular}

Abbreviations: IUD, intrauterine; IVR, intravaginal ring; NHP, nonhuman primate.

Pharmaceuticals, Petah Tivka, Israel). Available LNG-IUS systems include Mirena ${ }^{\circledR}(32 \times 32 \mathrm{~mm} ; 20 \mu \mathrm{g}$ of LNG released per 24 hours; Bayer Healthcare Pharmaceuticals, Wayne, NJ, USA) and Skyla ${ }^{\circledR}(28 \times 28 \mathrm{~mm} ; 14 \mu \mathrm{g}$ per 24 hours; Bayer Healthcare Pharmaceuticals). ${ }^{39}$ Intrauterine contraception is associated with an excellent contraceptive efficacy rate, comparable with that of tubal ligation, and requires less reliance on user compliance than other contraceptive methods. ${ }^{40}$ In some women, the LNG-IUS also confers noncontraceptive benefits such as amenorrhea. ${ }^{41}$

Larger species of nonhuman primate such as the baboon have a uterine lumen size that can accommodate humanuse IUDs. An LNG-IUS (Mirena ${ }^{\circledR}$ ) can be transcervically deployed in the baboon uterus. In ex vivo and in vivo evaluation of LNG-IUS placement in three baboons, magnetic resonance imaging and transabdominal ultrasound indicated successful uterine fundic deployment of the IUS. ${ }^{42}$ Successful implementation of a human-use copper IUD has been described in pigtail macaques. The GyneFix-200 mini ${ }^{\circledR}$ (Contrel Research, Ghent, Belgium) is a copper IUD consisting of four $5 \times 2.2 \mathrm{~mm}$ cylinders on a suture. Devices were placed via hysterotomy and maintained for 3 months. ${ }^{43}$

As suggested by the aforementioned studies, species differences in cervical anatomy affect whether devices can be deployed transcervically or require hysterotomy for placement. Unlike the baboon, which has a relatively straight cervical canal, ${ }^{42}$ the cervix of most macaque species is sigmoidal, making transcervical deployment of IUDs impractical. ${ }^{44}$ The necessity for IUD placement via hysterotomy and use of retention sutures may incite a local inflammatory response that can impact interpretation of data on toxicity and contraceptive efficacy. Interestingly, a recent study reports successful transcervical delivery of polidocanol foam in the rhesus macaque. ${ }^{45}$ Atraumatic cervical cannulation was achieved with ultrasonographic or laparoscopicguided placement of a series of cannulas used for gradual cervical dilation. This technique was not successful with all animals, however, and requires significant technical expertise. Similarly, nonsurgical transcervical cannulation in the rabbit has been reported, ${ }^{46}$ although not in the context of intrauterine system placement. The ability to atraumatically cannulate the rabbit cervix may increase its utility as an animal model for IUD development.

Modification of the IUD shape and size is typically required for smaller species. A straight silicone elastomer ("silastic") rod or a single silk, nylon, or copper filament ${ }^{47}$ has been utilized as an experimental alternative in smaller nonhuman primates and nonprimate animal models of intrauterine contraception. This type of device can be successfully implemented in many species, including rodents, with modifications easily made for individual variations in uterine size. Tubes can also be loaded with different pharmaceutical agents. For example, in one study that sought to evaluate the impact of an antiprogestin-releasing IUD in stump-tailed macaques, a $12 \mathrm{~mm}$ silastic tube was used to deliver one of three compounds with antiprogestin activity. ${ }^{28}$ Tubes were placed in the uterine body lumen via hysterotomy and migration prevented with a myometrial stay suture. Successful deployment of similar rod-shaped devices of lengths ranging from $10 \mathrm{~mm}$ to $15 \mathrm{~mm}$ are reported in other nonhuman primate studies. ${ }^{27} \mathrm{~A}$ filamentous IUD model has been well established in mice, rats, and guinea pigs. ${ }^{48-50}$ In these models, 
a single length of silk or other monofilament suture is placed transcervically within a single uterine horn. The contralateral horn is used as a control. Other devices successfully deployed via hysterotomy in rodents include copper or silicone rods ${ }^{51-53}$ and metal or silicone coils. ${ }^{54}$ Successful placement of IUDs from $5 \mathrm{~mm}$ to $35 \mathrm{~mm}$ in length are described in these studies. While the rod or filament IUDs offer flexibility with regard to scale and compound delivery, they do not necessarily mimic the biomechanical properties of larger IUDs.

This variability in size and type of device tested in preclinical studies has impacted our understanding of the contraceptive mechanism of action of the IUD. In both humans and animals, the mechanism of action is likely multimodal, occurring through alterations in the cervical mucous plug, endometrial receptivity, and germ cell or embryonic viability. ${ }^{55}$ It is important to understand the contraceptive mechanism of action of the IUD, as it may impact user acceptability in light of patient preference for avoidance of post-fertilization effects. ${ }^{56}$ In mice and rats, embryonic destruction within the uterine lumen is correlated with the presence of luminal polymorphonuclear leukocytes in the presence of a filamentous or copper IUD. ${ }^{57,58}$ In women, evidence suggests that pre-fertilization destruction of oocytes or sperm may be the more common contraceptive mechanism, particularly with the copper IUD. ${ }^{55,59,60}$ However, study of pre-fertilization events is difficult to perform noninvasively in women, and conclusions have been drawn from relatively small sample sizes. Therefore, it would be advantageous to prospectively evaluate the mechanism of action of the IUD in an animal model. However differences in IUD size and placement, as well as species-specific differences in reproductive physiology, have been difficult to overcome.

\section{Intravaginal rings}

An intravaginal ring (IVR) releasing etonogestrel and ethinyl estradiol (NuvaRing ${ }^{\mathbb{R}}$; Merck and Co, Whitehouse Station, NJ, USA) is currently approved for contraceptive use in the USA. IVRs offer an appealing means of drug delivery. Transmucosal vaginal drug delivery results in good bioavailability and comparable pharmacodynamic effects, without the side effects associated with oral administration. ${ }^{61}$ Moreover, IVRs offer a coitally independent means of drug delivery that is associated with high levels of user acceptability. ${ }^{61}$ Most preclinical studies of IVRs have been performed in macaque species and sheep. ${ }^{62-66}$

Recently, significant efforts towards development of combined contraceptive and microbicide delivery via IVR have resulted in a renewed interest in preclinical testing of vaginal ring models. ${ }^{62}$ Scaling of IVR size, stiffness, and surface area can present translational challenges. Promadej-Lanier et al tested three different IVR sizes in pigtail and rhesus macaques, and in both species, a $25 \mathrm{~mm}$ circumferential and $5 \mathrm{~mm}$ cross-sectional diameter silicone ring was associated with minimal induction of proinflammatory cytokines in the lower reproductive tract. ${ }^{63}$ Additionally, no visual evidence of irritation or inflammation was noted on colposcopic evaluation, although the smaller ring was significantly stiffer than commercially available models. This model of ring has since been used in several studies evaluating IVR delivery of antiretroviral agents in both pigtailed and cynomolgus macaques. ${ }^{64-66}$ These studies report acceptable levels of ring retention, although one noted that on necropsy 28 days post-placement, $25 \times 5 \mathrm{~mm}$ rings were located mid-vagina in the smaller cynomolgus macaque. ${ }^{66}$ Subsequent trials with a $20 \times 4.5 \mathrm{~mm}$ ring were associated with successful pericervical retention.

Differences in scale and vaginal $\mathrm{pH}$ also present challenges to interpretation of pharmacokinetic data. For example, in vivo IVR delivery of the microbicide dapirivine was evaluated in the cynomolgus macaque. ${ }^{66}$ Vaginal fluid concentrations of dapirivine were significantly lower than those reported from previous human clinical trials. The macaque vagina is more basic $(\mathrm{pH} 7)$ than that of the human ( $\mathrm{pH} 4$ ). The more basic vaginal environment may result in differences in drug protonation and consequent pharmacodynamic properties. Furthermore, the larger human IVR has a correspondingly greater surface area for drug delivery than the smaller macaque ring. It should also be noted that differences in vaginal epithelial morphology exist even between the different macaque species. For example, the vaginal epithelium of the rhesus macaque is more keratinized than that of humans or pigtail macaques. ${ }^{67}$ Care should therefore be taken when extrapolating the pharmacokinetics of vaginally delivered topical drugs between species.

The sheep is a potential preclinical alternative to the nonhuman primate for evaluation of IVRs. Advantages of the sheep model include a body mass and cervicovaginal canal size similar to women. Visual and histologic evaluation of the reproductive tract may be performed with ease. The sheep vagina is lined by stratified squamous epithelium, and although the vaginal submucosa is thinner than in humans, ${ }^{68}$ the vaginal epithelium of the sheep does not undergo pronounced histologic changes coincident with the estrous cycle, as is observed in the rodent. ${ }^{69}$ Disadvantages of the sheep model include a seasonal estrous cycle and a paucity of data on reproductive tract mucosal immunology. As a result of the sheep's larger size, human-sized IVRs can 
be tested without the scaling issues previously discussed. For example, the pharmacokinetic and toxicologic properties of a hydrophilic polyurethane IVR loaded with tenofovir were evaluated in sheep. ${ }^{70} \mathrm{~A} 55 \times 5.5 \mathrm{~mm}$ ring was used, which is comparable to the size of the NuvaRing $(54 \times 4 \mathrm{~mm})$. These rings were maintained for 90 days, with only one case of expulsion.

\section{Transdermal and subdermal delivery systems}

Transdermal delivery systems include patches, gels, and sprays. A single transdermal patch is currently on the US market for sustained delivery of ethinyl estradiol and norelgestromin (Ortho Evra ${ }^{\circledR}$; Janssen Pharmaceuticals, Inc., Beerse, Belgium). A 68 mg etonogestrel subdermal implant $\left(\right.$ Nexplanon $^{\circledR}$; Merck and Co) is also approved for use.

Transdermal drug absorption is affected by numerous variables, including species and drug characteristics. Amongst laboratory animal species, the pig, macaque, and rabbit are the most frequently utilized for study of topical drug applications. ${ }^{71}$ Porcine ear skin is frequently used in vitro for early preclinical validation of percutaneous drug permeation. ${ }^{72}$ Percutaneous absorption rates for testosterone and hydrocortisone as well nitroaromatic compounds is similar in vivo in rhesus macaques and humans. ${ }^{71}$ In a study examining transdermal patch formulations of levonorgestrel and 17 beta-estradiol, good correlation was found between in vivo pharmacokinetic and pharmacodynamic data in rabbits and the results of Phase I clinical trials in women. ${ }^{73}$ However, in percutaneous absorption studies of other hormonal compounds such as testosterone, data from rabbits is not predictive of human values. ${ }^{71}$ Study of subdermal drug delivery is less impacted by heterogeneity of skin morphology than transdermal formulations; however, as with oral drug delivery, it is subject to species differences in drug distribution and metabolism. A comprehensive discussion of preclinical evaluation of injectable or oral contraceptives is beyond the scope of this review, so we direct the reader to an excellent review by Andersson et al for a more detailed analysis of assessment of circulating female reproductive hormones in animal models. ${ }^{29}$

\section{Extra-contraceptive effects}

Drug or device extra-contraceptive effects may impact user health and safety as well as method acceptability. Animal models are useful for characterization of contraceptive offtarget effects where human studies are unethical or otherwise not feasible. For example, it is difficult to evaluate the interaction between sexually transmitted infection (STI) rates and hormonal contraception in human populations due to significant confounds, such as condom use. Condoms prevent STIs but are used at significantly lower rates by individuals employing other contraceptive methods. ${ }^{74}$ In particular, equivocal evidence on a causal relationship between human immunodeficiency virus acquisition and depot medroxyprogesterone acetate use in women ${ }^{75}$ has increased interest in modeling this interaction using macaques infected with unmodified or recombinant simian immunodeficiency virus (SIV or SHIV, respectively). These models were recently reviewed in a publication by McNicholl et al. ${ }^{76}$ The same group has also developed a model of SHIV infection in copper IUD-implanted pigtail macaques. ${ }^{43}$ In addition to SHIV, well characterized nonhuman primate models of Chlamydia trachomatis, ${ }^{77}$ Mycoplasma genitalium, ${ }^{78}$ Trichomonas vaginalis, ${ }^{79}$ and genital papillomavirus ${ }^{80}$ have been developed, and could be utilized for pathogen challenge studies of combined contraceptives.

Additionally, the vaginal microbiota of many species of nonhuman primate have been described both with ${ }^{81}$ and without a contraceptive device. ${ }^{82}$ As vaginal microbiota may contribute to host mucosal immune function, characterization of alterations in these bacterial communities is of particular importance for development of dual-action vaginal rings or IUDs that provide simultaneous contraception and microbicide-mediated STI protection. Several broad-spectrum microbicides have failed in clinical trials due to induction of mucosal damage with repeated use and increased risk of transmission of human immunodeficiency virus. ${ }^{62}$ Use of more stringent preclinical product selection criteria, including description of the impact of a product on vaginal microbiota, may enhance understanding of microbicide epithelial toxicity and STI acquisition risk with contraceptive or dual-action products in a well characterized pathogen challenge model.

Associations between contraceptive use and obesity can also be explored in animal models. Although systematic review suggests no causal relationship between weight gain and combined oral contraception (COC), weight gain is a common complaint in COC users. ${ }^{83}$ The impact of COC (ethinyl estradiol/LNG) on body weight, physical activity, caloric intake, percent body fat, and basal metabolic rate was compared in cohorts of healthy and obese female rhesus macaques over an 8-month treatment period. A 9\% decrease in body weight was observed in the obese animals, with no significant difference observed in the normal animals. A significant increase from baseline in basal metabolic rate 
was observed with $\mathrm{COC}$ treatment in both groups. ${ }^{84} \mathrm{~A}$ study using the same $\mathrm{COC}$ dosing protocol observed increases in both serum adiponectin and resistin from baseline in both obese and healthy weight macaques. ${ }^{85}$

\section{Conclusion}

Validated animal models are crucial for preclinical prediction of drug safety and efficacy that cannot be determined in vitro. Due to similarities with humans in reproductive anatomy and physiology, nonhuman primates are attractive candidates for modeling of contraceptive devices, understanding of their contraceptive mechanism of action, and evaluation of contraceptive efficacy. Other species, such as rodents or rabbits, also serve important roles in preclinical dosing optimization, safety pharmacology, and contraceptive target discovery. Leverage of extensive genetic and phenotypic tools in murine models has enabled discovery of pathways in reproductive biology suitable for contraceptive intervention. However, interspecies differences in follicular, luteal, and endometrial dynamics may reduce the translatability of these discoveries. Nevertheless, with careful thought given to selection of animal models, preclinical modeling enhances contraceptive development and ultimately improves patient safety and contraceptive choice worldwide.

\section{Disclosure}

The authors report no conflicts of interest in this work.

\section{References}

1. Alkema L, Kantorova V, Menozzi C, Biddlecom A. National, regional, and global rates and trends in contraceptive prevalence and unmet need for family planning between 1990 and 2015: a systematic and comprehensive analysis. Lancet. 2013;381(9878):1642-1652.

2. Brown SS, Eisenberg L, editors. The Best Intentions: Unintended Pregnancy and the Well-Being of Children and Families. Washington, DC, USA: National Academies; 1995.

3. Craig AD, Dehlendorf C, Borrero S, Harper CC, Rocca CH. Exploring young adults' contraceptive knowledge and attitudes: disparities by race/ ethnicity and age. Womens Health Issues. 2014;24(3):e281-e289.

4. Bartz D, Shew M, Ofner S, Fortenberry JD. Pregnancy intentions and contraceptive behaviors among adolescent women: a coital event level analysis. J Adolesc Health. 2007;41(3):271-276.

5. Bracken J, Graham CA. Young women's attitudes towards, and experiences of, long-acting reversible contraceptives. Eur J Contracept Reprod Health Care. 2014;19(4):276-284.

6. Bahamondes L, Bahamondes MV. New and emerging contraceptives: a state-of-the-art review. Int J Womens Health. 2014;6:221-234.

7. Nass SJ, Strauss JF 3rd. Strategies to facilitate the development of new contraceptives. Nat Rev Drug Discov. 2004;3(10):885-890.

8. Bavister BD. ARTs in action in nonhuman primates: symposium summary - advances and remaining issues. Reprod Biol Endocrinol. 2004;2:43.

9. Jinek M, Chylinski K, Fonfara I, Hauer M, Doudna JA, Charpentier E. A programmable dual-RNA-guided DNA endonuclease in adaptive bacterial immunity. Science. 2012;337(6096):816-821.
10. Kim IY, Shin JH, Seong JK. Mouse phenogenomics, toolbox for functional annotation of human genome. BMB Rep. 2010;43(2): 79-90.

11. Archambeault DR, Matzuk MM. Disrupting the male germ line to find infertility and contraception targets. Ann Endocrinol (Paris). 2014; 75(2):101-108.

12. Gupta N, Chakrabarti K, Prakash K, Wadhwa N, Gupta T, Gupta SK. Immunogenicity and contraceptive efficacy of Escherichia coli-expressed recombinant porcine zona pellucida proteins. Am J Reprod Immunol. 2013;70(2):139-152.

13. Naz RK. Antisperm contraceptive vaccines: where we are and where we are going? Am J Reprod Immunol. 2011;66(1):5-12.

14. Gupta SK, Shrestha A, Minhas V. Milestones in contraceptive vaccines development and hurdles in their application. Hum Vaccin Immunother. 2014;10(4):911-925.

15. Nie G, Findlay JK, Salamonsen LA. Identification of novel endometrial targets for contraception. Contraception. 2005;71(4):272-281.

16. Liu YX, Gao F, Wei P, et al. Involvement of molecules related to angiogenesis, proteolysis and apoptosis in implantation in rhesus monkey and mouse. Contraception. 2005;71(4):249-262.

17. Dias JA, Campo B, Weaver BA, et al. Inhibition of follicle-stimulating hormone-induced preovulatory follicles in rats treated with a nonsteroidal negative allosteric modulator of follicle-stimulating hormone receptor. Biol Reprod. 2014;90(1):19.

18. van de Lagemaat R, van Koppen CJ, Krajnc-Franken MA, et al Contraception by induction of luteinized unruptured follicles with short-acting low molecular weight FSH receptor agonists in female animal models. Reproduction. 2011;142(6):893-905.

19. Peluffo MC, Stanley J, Braeuer N, et al. A prostaglandin E2 receptor antagonist prevents pregnancies during a preclinical contraceptive trial with female macaques. Hum Reprod. 2014;29(7):1400-1412.

20. Nallasamy S, Kim J, Sitruk-Ware R, Bagchi M, Bagchi I. Ulipristal blocks ovulation by inhibiting progesterone receptor-dependent pathways intrinsic to the ovary. Reprod Sci. 2013;20(4):371-381.

21. Peluffo MC, Murphy MJ, Baughman ST, Stouffer RL, Hennebold JD Systematic analysis of protease gene expression in the rhesus macaque ovulatory follicle: metalloproteinase involvement in follicle rupture. Endocrinology. 2011;152(10):3963-3974.

22. Conti M, Andersen CB, Richard FJ, Shitsukawa K, Tsafriri A. Role of cyclic nucleotide phosphodiesterases in resumption of meiosis. $\mathrm{Mol}$ Cell Endocrinol. 1998;145(1-2):9-14.

23. Jensen JT, Stouffer RL, Stanley JE, Zelinski MB. Evaluation of the phosphodiesterase 3 inhibitor ORG 9935 as a contraceptive in female macaques: initial trials. Contraception. 2010;81(2):165-171.

24. Aschenbach LC, Hester KE, McCann NC, Zhang JG, Dimitriadis E, Duffy DM. The LIF receptor antagonist PEGLA is effectively delivered to the uterine endometrium and blocks LIF activity in cynomolgus monkeys. Contraception. 2013;87(6):813-823.

25. Ghosh D, Sengupta J. Target-oriented anti-implantation approaches for pregnancy interception: experiences in the rhesus monkey model. Contraception. 2005;71(4):294-301.

26. Slayden OD, Chwalisz K, Brenner RM. Reversible suppression of menstruation with progesterone antagonists in rhesus macaques. Hum Reprod. 2001;16(8):1562-1574.

27. Brenner RM, Slayden OD, Nath A, Tsong YY, Sitruk-Ware R. Intrauterine administration of CDB-2914 (ulipristal) suppresses the endometrium of rhesus macaques. Contraception. 2010;81(4):336-342.

28. Nayak NR, Slayden OD, Mah K, Chwalisz K, Brenner RM. Antiprogestin-releasing intrauterine devices: a novel approach to endometrial contraception. Contraception. 2007;75(6 Suppl):S104-S111.

29. Andersson H, Rehm S, Stanislaus D, Wood CE. Scientific and regulatory policy committee (SRPC) paper: assessment of circulating hormones in nonclinical toxicity studies III. Female reproductive hormones. Toxicol Pathol. 2013;41(6):921-934.

30. Stouffer RL, Bishop CV, Bogan RL, Xu F, Hennebold JD. Endocrine and local control of the primate corpus luteum. Reprod Biol. 2013;13(4) 259-271. 
31. Tardif S, Carville A, Elmore D, Williams LE, Rice K. Reproduction and breeding of nonhuman primates. In: Abee CR, Mansfield K, Tardif S, Morris T, editors. Nonhuman Primates in Biomedical Research. 2nd ed. Boston, MA, USA: Academic Press; 2012.

32. Micks E, Shekell T, Stanley J, et al. Medical termination of pregnancy in cynomolgus macaques. J Med Primatol. 2012;41(6):394-402.

33. Chaffin CL, Dissen GA, Stouffer RL. Hormonal regulation of steroidogenic enzyme expression in granulosa cells during the peri-ovulatory interval in monkeys. Mol Hum Reprod. 2000;6(1):11-18.

34. Westwood FR. The female rat reproductive cycle: a practical histological guide to staging. Toxicol Pathol. 2008;36(3):375-384.

35. Guy AJ, Schuerch FS, Heffernan S, Thomson PC, O'Brien JK, McGreevy PD. The effect of medroxyprogesterone acetate on behavioural responses of captive female hamadryas baboons (Papio hamadryas). Anim Reprod Sci. 2008;108(3-4):412-424.

36. Zelinski-Wooten MB, Slayden OD, Chwalisz K, Hess DL, Brenner RM, Stouffer RL. Chronic treatment of female rhesus monkeys with low doses of the antiprogestin ZK 137 316: establishment of a regimen that permits normal menstrual cyclicity. Hum Reprod. 1998;13(2): 259-267.

37. Hotchkiss J, Atkinson LE, Knobil E. Time course of serum estrogen and luteinizing hormone ( $\mathrm{LH}$ ) concentrations during the menstrual cycle of the rhesus monkey. Endocrinology. 1971;89(1):177-183.

38. Behboodi E, Katz DF, Samuels SJ, Tell L, Hendrickx AG, Lasley BL. The use of a urinary estrone conjugates assay for detection of optimal mating time in the cynomolgus macaque (Macaca fascicularis). $J$ Med Primatol. 1991;20(5):229-234.

39. Hardeman J, Weiss BD. Intrauterine devices: an update. Am Fam Physician. 2014;89(6):445-450.

40. Winner B, Peipert JF, Zhao Q, et al. Effectiveness of long-acting reversible contraception. N Engl J Med. 2012;366(21):1998-2007.

41. Gemzell-Danielsson K, Schellschmidt I, Apter D. A randomized, phase II study describing the efficacy, bleeding profile, and safety of two low-dose levonorgestrel-releasing intrauterine contraceptive systems and Mirena. Fertil Steril. 2012;97(3):616-622.

42. Bell JD, Bergin IL, Natavio MF, et al. Feasibility of LNG-IUS in a baboon model. Contraception. 2013;87(3):380-384.

43. Engel RM, Morris M, Henning T, et al. Evaluation of pigtail macaques as a model for the effects of copper intrauterine devices on HIV infection. J Med Primatol. 2014;43(5):349-359.

44. Hafez ESE, Jaszczak S. Comparative anatomy and histology of the cervix uteri in non-human primates. Primates. 1972;13(3):297-316.

45. Jensen JT, Hanna C, Yao S, et al. Blockade of tubal patency following transcervical administration of polidocanol foam: initial studies in rhesus macaques. Contraception. 2014;89(6):540-549.

46. Post JH, Cardella JF, Wilson RP, et al. Experimental nonsurgical transcervical sterilization with a custom-designed platinum microcoil. J Vasc Interv Radiol. 1997;8(1 Pt 1):113-118.

47. Doyle LL, Margolis AJ. Intrauterine foreign body. I. Effect on reproductive processes in the rat. Fertil Steril. 1964;15:597-606.

48. Bilbruck J, Hanlon GW, Gard PR, Martin GP. The effects of transcervical monofilament insertion on the microbial status of the uterus in guinea-pigs. J Pharm Pharmacol. 1994;46(3):213-216.

49. Ozalp S, Tanir HM, Cakmak B, Hassa H. Impact of piroxicam betacyclodextrin on the efficacy of the intrauterine device in a rat model. Eur J Contracept Reprod Health Care. 2007;12(2):107-110.

50. Gard PR, Reynolds JP, Hanlon GW. Use of chlorhexidine-releasing nylon fibres to reduce device-related uterine infections. Gynecol Obstet Invest. 2000;49(4):261-265.

51. Celik O, Ugras M, Hascalik S, Aydin NE, Abbasov T. Enhanced endometrial response to a magnetic intrauterine device: a preliminary study. Eur J Contracept Reprod Health Care. 2009;14(6): 437-443.

52. Zhang X, Yuan H, Deng L, Hu F, Ma J, Lin J. Evaluation of the efficacy of a danazol-loaded intrauterine contraceptive device on adenomyosis in an ICR mouse model. Hum Reprod. 2008;23(9):2024-2030.
53. Peng X, Hu S, Meng T, Suo J, Xiong C. The antifertility effectiveness of a novel copper-containing composite used in intrauterine contraceptive devices and the releasing behavior of cupric ions contained in the composite in rats. Contraception. 2012;86(4):413-418.

54. Qiu Y, Wang LG, Zhang MH, Zhang YP, Zhang AD, Yang DT. A new experimental three-dimensional, reticular intrauterine device (3-DRIUD) composed of nitinol and silicone rubber. Contraception. 2013;88(1):31-36.

55. Ortiz ME, Croxatto HB. Copper-T intrauterine device and levonorgestrel intrauterine system: biological bases of their mechanism of action. Contraception. 2007;75(6 Suppl):S16-S30.

56. Larimore WL, Stanford JB. Postfertilization effects of oral contraceptives and their relationship to informed consent. Arch Fam Med. 2000;9(2):126-133.

57. Batta SK, Chaudhury RR. The anti-implantation property of intraluminal fluid in rats with an intra-uterine silk thread suture. J Reprod Fertil. 1968;16(1):145-146.

58. Hurst PR, Jefferies K, Eckstein P, Wheeler AG. Intrauterine degeneration of embryos in IUD-bearing mice. $J$ Reprod Fertil. 1977;50(1): 187-189.

59. Stanford JB, Mikolajczyk RT. Mechanisms of action of intrauterine devices: update and estimation of postfertilization effects. Am J Obstet Gynecol. 2002;187(6):1699-1708.

60. Alvarez F, Brache V, Fernandez E, et al. New insights on the mode of action of intrauterine contraceptive devices in women. Fertil Steril. 1988;49(5):768-773.

61. Roumen FJ, Mishell DR Jr. The contraceptive vaginal ring, NuvaRing ${ }^{\circledR}$, a decade after its introduction. Eur J Contracept Reprod Health Care. 2012;17(6):415-427.

62. Veazey RS. Microbicide safety/efficacy studies in animals: macaques and small animal models. Curr Opin HIV AIDS. 2008;3(5): 567-573.

63. Promadej-Lanier N, Smith JM, Srinivasan P, et al. Development and evaluation of a vaginal ring device for sustained delivery of HIV microbicides to non-human primates. J Med Primatol. 2009;38(4):263-271.

64. Moss JA, Malone AM, Smith TJ, et al. Safety and pharmacokinetics of intravaginal rings delivering tenofovir in pig-tailed macaques. Antimicrob Agents Chemother. 2012;56(11):5952-5960.

65. Gunawardana M, Moss JA, Smith TJ, et al. Microbial biofilms on the surface of intravaginal rings worn in non-human primates. $J$ Med Microbiol. 2011;60 Pt 6:828-837.

66. Murphy DJ, Desjardins D, Dereuddre-Bosquet N, et al. Pre-clinical development of a combination microbicide vaginal ring containing dapivirine and darunavir. J Antimicrob Chemother. 2014;69(9): 2477-2488

67. Hadzic SV, Wang X, Dufour J, et al. Comparison of the vaginal environment of Macaca mulatta and Macaca nemestrina throughout the menstrual cycle. Am J Reprod Immunol. 2014;71(4):322-329.

68. Vincent KL, Bourne N, Bell BA, et al. High resolution imaging of epithelial injury in the sheep cervicovaginal tract: a promising model for testing safety of candidate microbicides. Sex Transm Dis. 2009;36(5): 312-318.

69. Touitou E, Barry BW. Enhancement in Drug Delivery. Boca Raton, FL, USA: CRC Press; 2007.

70. Johnson TJ, Clark MR, Albright TH, et al. A 90-day tenofovir reservoir intravaginal ring for mucosal HIV prophylaxis. Antimicrob Agents Chemother. 2012;56(12):6272-6283.

71. Godin B, Touitou E. Transdermal skin delivery: predictions for humans from in vivo, ex vivo and animal models. Adv Drug Deliv Rev. 2007;59(11):1152-1161.

72. Jacobi U, Kaiser M, Toll R, et al. Porcine ear skin: an in vitro model for human skin. Skin Res Technol. 2007;13(1):19-24.

73. Chien YW, Chien TY, Bagdon RE, Huang YC, Bierman RH. Transdermal dual-controlled delivery of contraceptive drugs: formulation development, in vitro and in vivo evaluations, and clinical performance. Pharm Res. 1989;6(12):1000-1010. 
74. ESHRI Capri Workshop Group. Simultaneous prevention of unintended pregnancy and STIs: a challenging compromise. Hum Reprod Update. 2014; 20(6):952-963.

75. Polis CB, Curtis KM. Use of hormonal contraceptives and HIV acquisition in women: a systematic review of the epidemiological evidence. Lancet Infect Dis. 2013;13(9):797-808.

76. McNicholl JM, Henning TC, Vishwanathan SA, Kersh EN. Non-human primate models of hormonal contraception and HIV. Am J Reprod Immunol. 2014;71(6):513-522.

77. Bell JD, Bergin IL, Harris LH, et al. The effects of a single cervical inoculation of Chlamydia trachomatis on the female reproductive tract of the baboon (Papio anubis). J Infect Dis. 2011;204(9):1305-1312.

78. Wood GE, Iverson-Cabral SL, Patton DL, Cummings PK, Cosgrove Sweeney YT, Totten PA. Persistence, immune response, and antigenic variation of Mycoplasma genitalium in an experimentally infected pig-tailed macaque (Macaca nemestrina). Infect Immun. 2013;81(8): 2938-2951.

79. Henning TR, Butler K, Hanson D, et al. Increased susceptibility to vaginal simian/human immunodeficiency virus transmission in pig-tailed macaques coinfected with Chlamydia trachomatis and Trichomonas vaginalis. J Infect Dis. 2014;210(8):1239-1247.
80. Wood CE, Chen Z, Cline JM, Miller BE, Burk RD. Characterization and experimental transmission of an oncogenic papillomavirus in female macaques. J Virol. 2007;81(12):6339-6345.

81. Hashway SA, Bergin IL, Bassis CM, et al. Impact of a hormonereleasing intrauterine system on the vaginal microbiome: a prospective baboon model. J Med Primatol. 2014;43(2):89-99.

82. Yildirim S, Yeoman CJ, Janga SC, et al. Primate vaginal microbiomes exhibit species specificity without universal Lactobacillus dominance. ISME J. 2014;8(12):2431-2444.

83. Mody SK, Han M. Obesity and contraception. Clin Obstet Gynecol. 2014;57(3):501-507.

84. Edelman A, Jensen JT, Bulechowsky M, Cameron J. Combined oral contraceptives and body weight: do oral contraceptives cause weight gain? A primate model. Hum Reprod. 2011;26(2):330-336.

85. Shaw KA, Hennebold JD, Edelman AB. Effect of a combined estrogen and progesterone oral contraceptive on circulating adipocytokines adiponectin, resistin and DLK-1 in normal and obese female rhesus monkeys. Contraception. 2013;88(1):177-182.
Open Access Journal of Contraception

\section{Publish your work in this journal}

Open Access Journal of Contraception is an international, peerreviewed, open access, online journal, publishing original research, reports, reviews and commentaries on all areas of contraception. In addition to clinical research, demographics and health-related aspects, the journal welcomes new findings in animal and preclinical studies

\section{Dovepress}

relating to understanding the biological mechanisms and practical development of new contraceptive agents. The manuscript management system is completely online and includes a very quick and fair peer-review system. Visit http://www.dovepress.com/testimonials.php to read real quotes from published authors.

Submit your manuscript here: http://www.dovepress.com/open-access-journal-of-contraception-journal 